Paidéia, 2004, 14 (28), 221-232

\title{
QUALIFICAÇÃO PROFISSIONAL E REPRESENTAÇÕES SOBRE TRABALHO E QUALIDADE DE VIDA ${ }^{1}$
}

\author{
Licia Barcelos de Souza ${ }^{2}$ \\ Marco Antonio de Castro Figueiredo \\ FFCLRP - Universidade de São Paulo
}

\begin{abstract}
Resumo: O esforço para conciliar trabalho e subjetividade determina no trabalhador um desgaste que incide sobre sua qualidade de vida. A busca pelo equilíbrio psico-afetivo, dentro deste "mundo" contraditório repercute na vida cotidiana, criando sistemas auto-agravantes de enfrentamento, que foram estudados com a participação de 16 profissionais de Campus da Universidade de São Paulo, em Ribeirão Preto. Para isso, foram realizadas entrevistas devolutivas sobre a percepção da qualidade de vida, avaliada pelo WHOQOL100. Entrevistas semi-estruturadas complementaram a avaliação com elementos sobre significados, sobre o trabalho e caracterização do contexto de vida. Estudos realizados sobre a qualificação dos profissionais apresentaram diferenças quanto às formas de enfrentamento e à busca do equilíbrio psico-afetivo, indicando, nos mais qualificados, uma dissociação entre o universo do trabalho e necessidades básicas para qualidade de vida, enquanto que para os menos qualificados o trabalho representou parte indissociável da sobrevivência.
\end{abstract}

Palavras-chave: trabalho; subjetividade; qualidade de vida.

\section{PROFESSIONAL QUALIFICATION AND REPRESENTATIONS ABOUT WORK AND QUALITY OF LIFE.}

\begin{abstract}
The effort to reconcile work and subjectivity is a source of wear for workers which affects their quality of life. The search for psycho-affective equilibrium within this contradictory "world" has repercussions on daily living, creating self-aggravating systems of coping which were studied in the present investigation with the participation of 16 professionals of the Ribeirão Preto Campus of the University of São Paulo. Feed - back interviews were held about the perception of quality of life as evaluated by the WHOQOL100 questionnaire. Semi-structured interviews complemented the evaluation by dealing with the meanings, of work and the characterization of the life context. Studies related to the qualifications of the professionals detected differences in the mode of coping and in the search for psycho-affective equilibrium, indicating a dissociation between the job universe and the basic needs of life quality among the more qualified subjects, whereas the job represented an undissociated part of survival among the less qualified subjects.
\end{abstract}

Key-Words: work; subjectivity; quality of life.

Este trabalho é uma síntese da experiência acumulada ao longo de 10 anos junto à Prefeitura do Campus Administrativo de Ribeirão Preto, à frente de um projeto de desenvolvimento de recursos humanos, que tinha por base a recuperação dos significados atribuídos pelo trabalhador ao seu trabalho.

\footnotetext{
${ }^{1}$ Artigo recebido para publicação em 11/02/2003; aceito em 10/09/2003. ${ }^{2}$ Endereço para correspondência: Lícia Barcelos de Souza, Departamento de Psicologia e Educação, Faculdade de Filosofia, Ciências e Letras de Ribeirão Preto, USP, Av. Bandeirantes, 3900, Monte Alegre, Ribeirão Preto, SP, Cep 14040-901, E-mail: liciabs@ffclrp.usp.br
}

Foram anos de enfrentamento à perda da compreensão da totalidade dentro de uma multiplicidade de atividades que subordinava as pessoas a um referencial já definido, planejado e afeto, a uma determinação externa à sua subjetividade.

Este distanciamento observado estava relacionado às questões de perda de auto-estima, busca de realizações externas ao trabalho, insegurança e falta de uma perspectiva que colocasse as pessoas diante do trabalho como seu sujeito, e portanto, com capacidade para transformá-lo. 


\section{Lícia Barcelos de Souza}

A pesquisa deste distanciamento permitiu, em uma dissertação de mestrado (Souza, 1995), lançar as bases de um trabalho mais avançado que identificasse, nesta perda da subjetividade, questões relativas à sobrevivência e às formas de enfrentamento das vicissitudes do trabalho, relacionando-as à qualificação e, portanto à organização do trabalho, como é feita dentro das estruturas funcionais da Universidade de São Paulo.

Este trabalho é, portanto, conseqüência de todo este processo, observado e vivenciado com os trabalhadores da USP de Ribeirão Preto, a quem deve ser atribuído qualquer valor instrumental que possa haver nesta pesquisa.

\section{Trabalho e Qualidade de Vida}

O conceito de qualidade de vida vem sendo utilizado nos campos da saúde e do trabalho, com o objetivo de verificar indicadores presentes nos vários contextos sociais e que possam sofrer intervenção através das políticas de saúde ou de estratégias de gestão empresarial.

De acordo com o grupo da Organização Mundial de Saúde, que desenvolveu o instrumento de avaliação utilizado no presente estudo, qualidade de vida pode ser definida como: “... a percepção do indivíduo de sua posição na vida no contexto da cultura e sistema de valores nos quais ele vive e em relação aos seus objetivos, expectativas, padrões e preocupações." (WHOQOL GROUP citado por Fleck, Leal, Louzada, Xavier, Chachamovich,Vieira, Santos \& Pinzon, 1999, pág. 20 )

No campo do trabalho, a Organização Internacional do Trabalho (OIT), lança em 1976 um plano de desenvolvimento que procura articular duas tendências:

“... uma dirigida ao melhoramento da qualidade geral de vida como aspiração básica para a humanidade hoje e que não pode sofrer solução de continuidade no portão da fábrica (...); a outra, concernente a uma maior participação dos trabalhadores nas decisões que diretamente dizem respeito à sua vida profissional" (Mendes apud Lacaz, 2000, pág. 152)
Diante destas perspectivas, podemos observar que tanto os aspectos presentes na organização do trabalho como os que se relacionam com a saúde, considerados indicadores de qualidade de vida, estão inseridos na ordem das contradições sociais e visam adequar os valores individuais aos interesses coletivos (Tamaki, 2000; Faerstein, 2000).

Heloani citada por Lacaz (2000), comenta que as políticas empresariais de programas de qualidade são caracterizadas por envolver mecanismos de controle da percepção e subjetividade, que visam a introjeção de normas e metas da empresa. Esta mesma contradição é apontada por outros autores:

“... a empresa, fazendo crer que seus interesses são coincidentes com os dos empregados, gera nestes o sentimento de participar dos objetivos da companhia, a qual, por sua vez, deve merecer seus esforços, contribuindo, assim, para o seu sucesso econômico....numa sutil estratégia para envolver os empregados numa ideologia manipulatória, levando-os a acreditar que, de fato estão fazendo algo que vem ao encontro de sua vontade." (Carmo apud Sampaio,1999, pág. 103)

Relacionando saúde e organização do trabalho, os efeitos da alienação e seus impactos na subjetividade dos trabalhadores vêm apresentando resultados interessantes. Estudos epidemiológicos, citados por Lacaz (2000), apontam para a ausência de autonomia do trabalhador sobre as condições de trabalho enquanto explicação para problemas de saúde, sofrimento mental e acidentes de trabalho, afetando sua qualidade de vida.

Outra questão interessante a ser citada é a que coloca as iniciativas de aumento de participação adotadas pelas empresas em contraposição às exigências de escolarização, aumento de responsabilidade, maior carga de trabalho e menor autonomia para o trabalhador, que repercutem negativamente na sua saúde física e mental: "Se, de um lado, a reestruturação exige o surgimento de um trabalhador participativo, escolarizado e polivalente, esta polivalência é vivenciada de forma ambígua, ou seja, como aumento de responsabilidade, maior carga de trabalho e menor autonomia". (Lacaz, pág. 157) 
Outras características importantes são citadas como decorrentes da divisão e da intensificação do trabalho reorganizado, que se referem à baixa autonomia de decisões, às atividades pouco criativas e pequeno apoio social, que também colaboram para o desgaste do trabalhador.

Portanto, os estudos que se referem aos impactos da organização do trabalho sobre a saúde e qualidade de vida do trabalhador apresentam múltiplas dimensões de análise. Identificar e compreender a determinação do trabalho nas condições de vida constitui um eixo importante para a análise da formação da subjetividade, representada pelas formas como o trabalhador percebe e organiza suas relações com o mundo "fora do trabalho", que contempla as outras esferas sociais e a utilização dos meios de acesso aos recursos sociais de educação, saúde, lazer entre outros.

\section{Referencial Teórico e Metodológico}

Segundo Minayo (1993), a teoria marxista é a teoria da ação humana nas transformações sociais onde o trabalho adquire o valor de determinação dessa ação humana, se constituindo em categoria mediadora das relações sociais, inserida por sua vez no modo de produção, historicamente determinado, que se apresenta como categoria básica na análise das sociedades:

"A categoria mediadora das relações sociais é o trabalho, a atividade prática. $O$ trabalho constitui um aspecto particular da ordem cultural mas tem valor de determinação dessa ordem: é através do trabalho que o reino da cultura se sobrepõe ao reino da natureza." (Marx apud Minayo 1993, pág. 73)

Assim, o trabalho, enquanto categoria histórica, determina e é determinado pelos modos de produção, sendo que as formas como o trabalho socialmente se organiza determinam outras estruturas das relações sociais.

Um dos pontos principais deste referencial teórico é a abordagem dialética das relações estabelecidas entre as categorias de análise, "que introduz na compreensão da realidade o princípio do conflito e da contradição como algo permanente e que explica a transformação." (Minayo, 1993, pág 68)

Abrangendo a totalidade do objeto de investigação através da compreensão de suas mediações numa perspectiva histórica, possibilita ampliar a dimensão de análise dos fatos psicológicos para fora dos limites da psicologia, transferindo o referencial do indivíduo psicologicamente descrito para a referência das determinações sociais num dado momento histórico.

Metodologicamente, a totalidade significa observar a realidade objetiva como um todo coerente e ao mesmo tempo compreender as partes que o integram, estabelecendo correlações de conjuntos e unidades.

As representações sociais, expressão das idéias e pensamentos, derivam da relação entre as idéias e a base material das formas de organização social, tendo como princípio básico na formação da consciência o modo de vida, determinando por sua vez pelo modo de produção.

A consciência então é considerada uma categoria de análise do "mundo das idéias", relativizando o determinismo econômico da base material de produção. Porém, o referencial do materialismo histórico introduz outro elemento importante na análise das representações sociais que trata da condição de classe enquanto determinante de relações sociais contraditórias.

As representações sociais da classe dominada são "idéias" determinadas pelas contradições entre seu lugar na produção e sua condição social. A consciência da desintegração se manifesta sob seu aspecto existencial e psicológico e não na crítica de como são estabelecidas as relações sociais na produção material da sociedade.

Assim, as representações sociais, tendo na linguagem a mediação para sua compreensão, devem ser consideradas como um instrumento importante para a análise do social, por expressar o fenômeno ideológico da comunicação da vida cotidiana: "Pela sua vinculação dialética com a realidade, a compreensão da fala exige ao mesmo tempo a compreensão das relações sociais que ela expressa." (Minayo, 1993, pág. 175) 


\section{Método}

\section{Sujeitos}

A pesquisa foi desenvolvida junto a uma amostra composta por 16 profissionais, de várias especialidades, escolhidos em número igual de homens e mulheres.

\section{Material}

Para avaliação da Qualidade de Vida foi utilizada a versão em português do World Health Organization Quality of Life (WHOQOL-100), desenvolvido pela Organização Mundial da Saúde. O instrumento é composto por 100 itens, com escalas do tipo Likert, que avaliam seis Domínios: Físico, Psicológico, Nivel de Independência, Relações Sociais, Ambiente e Espiritualidade. (Fleck e cols., 1999)

Para a avaliação da qualificação profissional, foi elaborado um questionário com 15 itens e aplicadas escalas tipo Likert. Os itens foram formulados com base nos critérios de Raridade, Importância, Indenização e Esforço. (Figueiredo, 1998):

Raridade: grau de disponibilidade de profissionais no mercado de trabalho, determinado pelo tempo e recursos pessoais e financeiros necessários para a formação e o nível de complexidade das habilidades exigidas para o desempenho profissional.

Importância: grau de responsabilidade exigido pela atividade profissional, tendo em vista a amplitude das conseqüências das decisões tomadas no âmbito da organização e para as pessoas que dependem dos serviços prestados.

Indenização: níveis de riscos aos quais o profissional está exposto no exercício da atividade, envolvendo riscos físicos, químicos, biológicos e de desgaste mental.

Esforço: nível da carga de esforço e desgaste, despendido para a execução das atividades, considerando as dimensões física e psicológica.

\section{Coleta de Dados}

A coleta de dados foi realizada em duas sessões individuais. Na primeira, foi aplicado o Questi- onário de Avaliação de Qualidade de Vida (WHOQOL-100). Na segunda, foram realizadas a entrevista semi-estruturada, a entrevista devolutiva dos resultados obtidos no WHOQOL-100 e a autoavaliação da Qualificação Profissional.

A entrevista semi-estruturada, gravada mediante consentimento informado dos profissionais, verificou quatro grupamentos de informações. A partir de questões estruturadas, foram verificados os dados de identificação, dados demográficos e a caracterização do contexto imediato de trabalho. Na segunda parte da entrevista, utilizando questões abertas, foram evocados os conteúdos associados aos Significados do Trabalho, aos Aspectos de Bem-estar e Aspectos de Mal-estar no trabalho.

A entrevista devolutiva do WHOQOL-100 consistiu em apresentar os resultados obtidos, solicitando aos profissionais que realizassem comentários acerca de suas impressões sobre os resultados. Finalizando a segunda sessão, foi auto-aplicado o questionário para avaliação da qualificação profissional.

\section{Análise dos Dados}

Conforme as orientações da Organização Mundial de Saúde, as respostas obtidas nos itens do instrumento para Avaliação da Qualidade de Vida (WHOQO1-100) foram submetidas às etapas definidas para cálculo dos escores. (Fleck \& cols., 1999)

Com o objetivo de estabelecer parâmetros para localização dos sujeitos no conjunto dos resultados da amostra, foram realizados estudos com base em estatística descritiva. Os dados quantitativos foram complementados com as informações obtidas nas entrevistas devolutivas.

Objetivando estabelecer parâmetros para análise da auto-avaliação da qualificação profissional, o mesmo questionário foi adaptado para ser respondido por 8 juízes, profissionais com formação superior e que atuam na área de recursos humanos e orientação profissional, que avaliaram as descrições de 13 atividades profissionais, baseadas no Plano de Classificação de Cargos da Universidade de São Paulo (Universidade de São Paulo, 1995) e na Classificação Brasileira de Ocupações do Ministério do Trabalho e do Emprego (Ministério do Trabalho e do Emprego, 2000). 
A análise dos resultados da avaliação do nível de Qualificação Profissional, obtidos pelos sujeitos e pelos especialistas, consistiu em estudos descritivos da distribuição dos índices relativos frente aos Princípios que compõem o instrumento. Também foram realizados estudos de validade de conteúdo que resultaram na classificação das atividades profissionais em dois grupos: Índice de Qualificação (IQ) Maior ou Menor que a Mediana.

A análise de conteúdo das entrevistas foi realizada em quatro fases (Fioroni, 2000), que compreenderam: a) a transcrição na íntegra, b) leituras do texto acompanhadas da audição da fita, c) identificação e recorte dos trechos cujos conteúdos estivessem relacionados aos temas abordados pelo roteiro de entrevista. Para cada trecho selecionado foram realizadas notações, que pudessem expressar o ponto de referência que o sujeito utilizou para compor suas percepções. Posteriormente foram identificadas as Unidades Temáticas a partir do grupamento de conteúdos das 16 entrevistas, segundo a convergência dos significados. A partir das sínteses das Unidades Temáticas, identificadas em cada Tema abordado, os resultados foram interpretados considerando a prevalência das verbalizações, determinada pelos critérios de qualificação profissional, definidos para nosso grupo de referência.

\section{Resultados}

Com base nos dados das entrevistas, foi verificado que no grupo de mulheres $50 \%$ concentrou-se na faixa de idade entre 30 e 40 anos, $37 \%$ era casada e $50 \%$ trabalhava na Universidade a pelo menos 10 anos. No grupo masculino $50 \%$ dos profissionais encontrava-se na faixa entre 40 e 50 anos, $87 \%$ era casado e $50 \%$ trabalhava há mais de 10 anos na Universidade. Considerando a totalidade da amostra foi verificada a distribuição dos sujeitos em quatro níveis de escolaridade: $12 \%$ com ensino fundamental incompleto, $31 \%$ fundamental completo, $19 \% \mathrm{com}$ ensino médio e 37\% com Superior.

A avaliação da Qualidade de Vida resultou em índices de satisfação frente aos Domínios e Facetas propostas pelo WHOQOL-100 (Fleck, 1999). Posteriormente, foram realizados estudos descritivos da distribuição dos índices de satisfação, consideran- do a amostra de 16 sujeitos. As medianas da distribuição indicaram uma maior satisfação com os aspectos que integram o Domínio Nível de Independência (.82), e a menor satisfação apresentada se referiu aos fatores avaliados pelo Domínio Físico (.60).

A análise do nível de qualificação das atividades profissionais permitiu classificar as funções em 2 níveis de qualificação, tomando-se como critério o Percentil 50 da distribuição dos Índices Relativos Gerais, obtidos no conjunto das avaliações dos especialistas frente às atividades profissionais:

Tabela 1: Grupamento das funções de acordo com o nível de Qualificação Profissional avaliado por Especialistas.

\begin{tabular}{|c|c|c|}
\hline Funções & $\mathbf{X}$ & $\begin{array}{c}\text { Grupos de Funções } \\
\qquad\left(\mathrm{P}_{50}=.63\right)\end{array}$ \\
\hline $\begin{array}{l}\text { Analista de Sistemas - } \\
\text { Chefe de Seção }(N=01) \\
\text { Biologista }(N=01) \\
\text { Educador em Prática } \\
\text { Desportiva }(N=01) \\
\text { Analista de Comunicação } \\
\text { Social }(N=01) \\
\text { Bibliotecário - } \\
\text { Chefe de Seção }(N=01) \\
\text { Secretária - } \\
\text { Chefe de Seção }(N=01) \\
\text { Bibliotecário }(N=01)\end{array}$ & $\begin{array}{l}.71 \\
.70 \\
.69 \\
.68 \\
.68 \\
.65 \\
.61\end{array}$ & $\begin{array}{c}\text { Índice } \\
\text { de } \\
\text { Qualificação } \\
\text { Superior } \\
\text { (acima de } \mathrm{P}_{50} \text { ) }\end{array}$ \\
\hline $\begin{array}{l}\text { Pedreiro }(N=02) \\
\text { Técnico de Manutenção } \\
\text { Eletrônica }(N=01) \\
\text { Cozinheira }(N=01) \\
\text { Zelador - } \\
\text { Chefe de Seção }(N=01) \\
\text { Encadernador }(N=01) \\
\text { Auxiliar de Serviços } \\
\text { Gerais }(N=01) \\
\text { Auxiliar de } \\
\text { Cozinha }(N=02)\end{array}$ & $\begin{array}{l}.61 \\
.61 \\
.58 \\
.53 \\
.50 \\
.50 \\
.48 \\
\end{array}$ & $\begin{array}{c}\text { Índice } \\
\text { de } \\
\text { Qualificação } \\
\text { Inferior } \\
\text { (abaixo de } \mathrm{P}_{50} \text { ) }\end{array}$ \\
\hline
\end{tabular}

Podemos observar que as atividades profissionais classificadas no grupo de Maior Qualificação $(N=06)$ exigem formação universitária específica elou encontram-se relacionadas com posições hierárquicas. No grupo de atividades com Menor Qualificação $(N=10)$ observamos características 
associadas à exigência de formação acadêmica nos níveis médio e fundamental, com exceção da profissão de Bibliotecário, e também o predomínio de habilidades operacionais. Desta forma, os resultados indicaram a utilização de critérios homogêneos pelos juizes em suas avaliações.

A partir dos três Temas abordados: a) Significados do Trabalho, b) Aspectos de Bem-Estar e Satisfação e c) Aspectos de Mal-Estar e Insatisfação associados ao trabalho, foram identificadas as Unidades Temáticas. Estudos de diferença de proporção apontaram prevalência de representações bem como conteúdos comuns entre os dois grupos. Os resultados são apresentados a seguir:

Quadro 1: Unidades Temáticas relacionadas aos "Significados do Trabalho".

\begin{tabular}{|c|c|c|c|}
\hline \multicolumn{4}{|c|}{ TEMA: "Significados do Trabalho" } \\
\hline $\begin{array}{l}\text { Ind. } \\
\text { Qual. }\end{array}$ & $\mathbf{P}$ & $\begin{array}{l}\text { Unidade } \\
\text { Temática }\end{array}$ & Síntese \\
\hline \multirow{2}{*}{$\begin{array}{l}\text { SUPE- } \\
\text { RIOR }\end{array}$} & .67 & $\begin{array}{c}\text { “TRABALHO } \\
E \\
\text { IDENTIDA- } \\
D E "\end{array}$ & $\begin{array}{c}\text { Elemento que } \\
\text { contribui para a } \\
\text { formação da iden- } \\
\text { tidade e expressão } \\
\text { da subjetividade. }\end{array}$ \\
\hline & .67 & $\begin{array}{c}\text { “TRABALHO } \\
E \\
\text { APRENDIZA- } \\
\text { GEM" }\end{array}$ & $\begin{array}{l}\text { Contexto que ofe- } \\
\text { rece possibilidades } \\
\text { de aprendizagem e } \\
\text { desenvolvimento } \\
\text { pessoal. }\end{array}$ \\
\hline \multirow{2}{*}{$\begin{array}{l}\text { INFE- } \\
\text { RIOR }\end{array}$} & .50 & $\begin{array}{c}\text { "TRABALHO } \\
E \\
\text { SAÚDE" }\end{array}$ & $\begin{array}{c}\text { Determinações do } \\
\text { trabalho sobre a } \\
\text { saúde física e } \\
\text { mental }\end{array}$ \\
\hline & .60 & $\begin{array}{c}\text { "TRABALHO } \\
E \\
\text { VIDA COTI- } \\
\text { DIANA" }\end{array}$ & $\begin{array}{l}\text { Importância do } \\
\text { trabalho na } \\
\text { estruturação e or- } \\
\text { ganização da vida } \\
\text { cotidiana }\end{array}$ \\
\hline $\begin{array}{l}\text { SuPE- } \\
\text { RIOR }\end{array}$ & .33 & $\begin{array}{c}\text { “TRABALHO } \\
E \\
\text { NECESSIDA- }\end{array}$ & $\begin{array}{l}\text { Meio de acesso } \\
\text { aos recursos } \\
\text { sociais e de so- }\end{array}$ \\
\hline $\begin{array}{l}\text { INFE- } \\
\text { RIOR }\end{array}$ & .40 & DES SUCIAIS & \\
\hline
\end{tabular}

No tema "Significados do Trabalho", as representações sobre o trabalho enquanto meio de satisfação de necessidades sociais foram comuns aos dois grupos. Para os profissionais com maior qualificação prevaleceram os conteúdos que remetem ao trabalho como importante fator de identidade social e meio de aprendizagem, enquanto que para os com menor qualificação prevaleceram as representações sobre o trabalho como elemento estruturante da vida cotidiana e indicador de saúde.

Quadro 2: Unidades Temáticas relacionadas aos "Aspectos de Bem-estar e Satisfação".

\begin{tabular}{|c|c|c|c|}
\hline \multicolumn{4}{|c|}{ TEMA: “Aspectos de Bem-estar e Satisfação” } \\
\hline $\begin{array}{l}\text { Ind. } \\
\text { Qual. }\end{array}$ & $\mathbf{P}$ & $\begin{array}{l}\text { Unidade } \\
\text { Temática }\end{array}$ & Síntese \\
\hline \multirow{4}{*}{$\begin{array}{l}\text { SUPE- } \\
\text { RIOR }\end{array}$} & .50 & $\begin{array}{c}\text { "COOPERA- } \\
\text { ÇAO SOCIAL" }\end{array}$ & $\begin{array}{l}\text { Significados atribuí- } \\
\text { dos às ações de } \\
\text { cooperação, troca } \\
\text { de informações e ao } \\
\text { sentimento de utili- } \\
\text { dade social }\end{array}$ \\
\hline & .33 & $\begin{array}{c}\text { "NÍVEL DE } \\
\text { COMPLEXIDA- } \\
\text { DE DAS ATIVI- } \\
\text { DADES" }\end{array}$ & $\begin{array}{l}\text { Representações } \\
\text { que explicitaram a } \\
\text { satisfação em re- } \\
\text { solver atividades } \\
\text { que exigem capaci- } \\
\text { dade de raciocínio. }\end{array}$ \\
\hline & .33 & $\begin{array}{l}\text { "RECONHECI- } \\
\text { MENTO PRO- } \\
\text { FISSIONAL” }\end{array}$ & $\begin{array}{l}\text { Satisfação em } \\
\text { obter reconheci- } \\
\text { mento e valoriza- } \\
\text { ção pelos resulta- } \\
\text { dos obtidos no } \\
\text { trabalho. }\end{array}$ \\
\hline & .33 & $\begin{array}{c}\text { "REALIZAÇÃO } \\
\text { DO TRABALHO } \\
\text { PRE-CONCE- } \\
\text { BIDO” }\end{array}$ & $\begin{array}{l}\text { Significados atri- } \\
\text { buídos à possibi- } \\
\text { lidade de realizar } \\
\text { uma atividade da } \\
\text { forma como foi } \\
\text { concebida. }\end{array}$ \\
\hline $\begin{array}{l}\text { INFE- } \\
\text { RIOR }\end{array}$ & .50 & $\begin{array}{c}\text { “AMPLIAÇÃO } \\
\text { DO CONTEXTO } \\
\text { SOCIAL” }\end{array}$ & $\begin{array}{l}\text { Várias formas de } \\
\text { relações sociais } \\
\text { estabelecidas no tra- } \\
\text { balho, enquanto ele- } \\
\text { mento importante } \\
\text { para o bem-estar. }\end{array}$ \\
\hline
\end{tabular}


Com relação aos "Aspectos de Bem-estar e Satisfação no Trabalho", foram identificadas representações comuns aos dois grupos, que fazem referência ao exercício da capacidade de raciocínio, ao reconhecimento profissional e controle do processo de trabalho. Para os profissionais com maior qualificação, a satisfação no trabalho encontra-se associada às ações de cooperação social, enquanto que para o grupo com menor qualificação, a possibilidade de ampliação do contexto social prevaleceu como importante aspecto de bem-estar no trabalho.

Quadro 3: Unidades Temáticas relacionadas aos "Aspectos de Mal-estar e Insatisfação".

\begin{tabular}{|c|c|c|c|}
\hline \multicolumn{4}{|c|}{ TEMA: "Aspectos de Mal-estar e Insatisfação" } \\
\hline $\begin{array}{l}\text { Ind. } \\
\text { Qual. }\end{array}$ & $\mathbf{P}$ & $\begin{array}{l}\text { Unidade } \\
\text { Temática }\end{array}$ & Síntese \\
\hline \multirow{2}{*}{$\begin{array}{l}\text { SUPE- } \\
\text { RIOR }\end{array}$} & .67 & $\begin{array}{c}\text { "FRACASSOS } \\
\text { NO DESEM- } \\
\text { PENHO" }\end{array}$ & $\begin{array}{l}\text { Representações sobre } \\
\text { o sentimento de culpa } \\
\text { gerado pelos erros } \\
\text { cometidos na execu- } \\
\text { ção do trabalho. }\end{array}$ \\
\hline & .50 & $\begin{array}{c}\text { "ESTRATÉGI- } \\
\text { AS DE CON- } \\
\text { TROLE" }\end{array}$ & $\begin{array}{l}\text { Insatisfações causa- } \\
\text { das pela submissão } \\
\text { às normas e formas } \\
\text { de controle exercidos } \\
\text { pela Organização. }\end{array}$ \\
\hline $\begin{array}{l}\text { INFE- } \\
\text { RIOR }\end{array}$ & .80 & $\begin{array}{c}\text { “CONFLITOS } \\
\text { NAS RELA- } \\
\text { ÇÕES DE TRA- } \\
\text { BALHO”" }\end{array}$ & $\begin{array}{l}\text { Conflitos que emer- } \\
\text { gem nas relações soci- } \\
\text { ais estabelecidas no } \\
\text { contexto de trabalho. }\end{array}$ \\
\hline
\end{tabular}

Para o grupo de profissionais com maior qualificação, a vivência de fracasso no desempenho e a submissão aos mecanismos de controle adotados pela Organização constituíram os principais "Aspectos de Insatisfação e Mal-estar" no trabalho, sendo que para os profissionais com menor qualificação prevaleceram as representações sobre conflitos emergentes no contexto das relações sociais do trabalho, enquanto fonte de insatisfação.

\section{Discussão}

Foi observada maior satisfação com os aspectos que integram o Domínio Nível de Independên- cia, e a menor satisfação apresentada se referiu aos fatores avaliados pelo Domínio Físico. Contrapondo estes resultados aos obtidos por Caldana (2000), em seu estudo sobre o impacto do desemprego na qualidade de vida, utilizando o mesmo instrumento de avaliação, foi observado que as pessoas excluídas da sociedade produtiva, se avaliaram como mais satisfeitas frente aos aspectos vinculados ao Domínio Espiritualidade e menos satisfeitas com os aspectos que integram o Domínio Ambiente.

A partir de uma análise inicial, podemos verificar que o trabalho ocupa um papel central na formação das percepções acerca da qualidade de vida (Lacaz, 2000), talvez por se caracterizar, no modo de produção capitalista, como uma explicação naturalizada para obtenção e acesso aos recursos sociais e de sobrevivência, e conseqüentemente determinar valores e sentidos à existência humana.

Aprofundando a análise dos resultados de nossos estudos, foi verificado que os profissionais que apresentaram as necessidades menos satisfeitas no Domínio Físico, desempenham atividades de menor qualificação e que exigem esforço físico e mobilidade. Nas entrevistas, relataram que enfrentam problemas em seus estados de saúde e também acumulam jornadas de trabalho ou estudo fora da Universidade. A questão da saúde para os trabalhadores é de certa forma fundamental para a garantia de permanecerem produtivos, principalmente em períodos de crise econômica, sendo que qualquer dificuldade encontrada pode representar uma ameaça de afastamento ou mesmo de exclusão do "mundo do trabalho" (Angerami-Camon,1986; Seligman-Silva, 1986; 1994).

Ainda a esse respeito, deve-se considerar que as implicações da qualidade de vida na saúde do trabalhador não podem ser vistas a partir de abordagens que se preocupem com a formação de hábitos de vida saudáveis. Por se situarem numa perspectiva individualizada e que não privilegiam as relações e a organização do processo de trabalho, enquanto categorias centrais para a explicação dos problemas atuais de saúde do trabalhador (Lacaz, 2000; Tamaki, 2000), acabam por minimizar uma problemática que é da ordem do coletivo.

$\mathrm{O}$ grupo de profissionais que se mostrou mais satisfeito com os fatores que avaliaram o Nível de 


\section{Lícia Barcelos de Souza}

Independência, apresentou uma característica interessante. Apesar das condições de vida satisfatórias, descritas na caracterização do contexto sócio-familiar e da dinâmica do cotidiano, identificamos que o ponto em comum se refere ao controle e autonomia nas decisões sobre os aspectos de seu modo de vida e da família, tendo como pano de fundo as formas de utilização dos rendimentos provenientes do trabalho assalariado. Portanto, na percepção destes profissionais a perspectiva de se auto-determinar, mesmo que direcionados pelos limites impostos pela renda familiar, pareceu conferir a satisfação com aspectos de independência.

A autonomia e controle sobre os meios de utilização dos recursos sociais disponíveis, que incidiram sobre a percepção da qualidade de vida, encontra uma situação correspondente quando se analisam as relações estabelecidas com o contexto de trabalho. A qualidade de vida não pode ser analisada sem se considerar o grau de controle e autonomia exercido pelos trabalhadores sobre seu trabalho, que faz com que se transformem em "sujeitos na situação" (Lacaz, 2000, pág. 154).

O estudo realizado sobre fatores de stress em diferentes categorias profissionais, realizado por Chan, Lai,, Ko \& Kam, (2000), mostrou que os profissionais com melhor qualificação e principalmente que exercem maior autonomia e controle sobre o processo de trabalho, apresentaram melhores condições de enfrentamento de situações causadoras de desgaste mental.

Tomando como referência os índices de satisfação obtidos nos Indicadores Globais e a composição do contexto social e familiar, os profissionais que se sentiram mais satisfeitos com sua qualidade de vida foram aqueles que dispõem de autonomia sobre as decisões do dia-a-dia, e não necessariamente condições materiais de vida plenamente satisfatórias, o que pode contribuir para uma visão mais otimista ou conformada sobre as determinações de seu modo de vida. Neste sentido, pode-se constatar também que as percepções estão pautadas num modo de ser individualizado, pouco voltado para outras questões que não aquelas que se referem aos próprios interesses.

Os profissionais do grupo menos satisfeito com sua qualidade de vida relataram nas entrevistas que vêm passando por problemas de depressão, o que sem dúvida pode ter interferido sobre sua percepção da qualidade de vida ao responderem o instrumento. Mesmo assim, nas questões relacionadas à percepção da satisfação das necessidades, foi interessante observar que neste grupo encontram-se pessoas com condições de vida material desfavoráveis e favoráveis, o que mais uma vez leva a pensar sobre o caráter subjetivo das percepções sobre qualidade de vida (Lacaz, 2000; Sampaio, 1999; Tamaki, 2000), sendo que a questão psicológica subordina a material.

A contraposição entre a satisfação de interesses individuais e coletivos remete a discussão sobre qualidade de vida para o âmbito das relações sociais, que enfatizam a lógica de uma cultura individualizada em detrimento da consciência de valores coletivos.

Novamente, os resultados apontaram para as diferentes formas de como a organização social e do trabalho, no modo de produção capitalista, trata os diferentes subgrupos definidos pela divisão social do trabalho (Braverman, 1987; Carmo, 1992; Gorz, 1989; Villalobos, 1978). Os profissionais com maior qualificação acabam ocupando um lugar diferenciado nas relações de trabalho, definido pelo maior acesso às informações e, portanto, desenvolvem uma percepção mais crítica e exigente acerca das necessidades a serem supridas pela venda de sua força de trabalho, que também é determinada pelas condições de vida mais favoráveis e pelo maior acesso aos recursos sociais que garantem saúde, escolarização e consumo de bens e serviços.

Assim, retomando os resultados, pode-se perceber que o nível de qualificação profissional, considerando o conjunto de seus determinantes, configurou um importante indicador das diferenças encontradas na percepção da qualidade de vida, quanto aos aspectos de saúde e autonomia para o enfrentamento do contexto de vida.

A Unidade Temática sobre os "Significados do Trabalho", que se referiu ao trabalho enquanto meio de acesso aos recursos sociais e de sobrevivência, reuniu as concepções dos dois grupos de profissionais. Nas representações do trabalho enquanto meio de satisfação de necessidades sociais, foram verificadas tendências diferentes entre as falas dos profissionais, segundo o nível de qualificação. 


\section{Qualificação Profissional 229}

Para os profissionais com maior qualificação, as expectativas de acesso aos recursos sociais apresentaram-se associadas às necessidades despertadas pela cultura de consumo, ilustradas na fala do sujeito 15 :

"eu te falei no início, que nem, ele é importante porque tudo que eu tenho, na verdade, você consegue a partir dele, né? Que nem, é uma luta você conseguir o seu lugar ao sol, aquelas coisas, então pra mim é importante. “(biólogo)

Para os profissionais com menor qualificação, além da expectativa de consumo, o trabalho representou o único meio de garantia das condições mínimas de sobrevivência e de manter uma perspectiva de melhoria de condições de vida para os descendentes. Os significados que atribuíram ao trabalho o papel de elemento que estrutura a vida cotidiana, identificando na rotina de trabalho a sensação de segurança e de direção, foram predominantes nas falas do grupo de profissionais de menor qualificação, o que legitima as expectativas de satisfação de necessidades sociais básicas através do trabalho. As falas dos sujeitos 5 e 11 demonstram estas expectativas:

“...E... prá, trabalhá prá gente tê as coisa, dá educação pros filho é... " (auxiliar de serviços gerais)

"Ah, sem trabalho num vive direito. É maravilhoso, (risos) é importante cê sabê que cê levanta, que cê tem onde cê i trabalhá. Que bom, isso dai dá uma certa perspectiva na vida da gente. Dá. Pelo menos pra mim dá, né? "(pedreiro)

O sentimento de impotência gerado pelas limitações impostas pelo poder aquisitivo frente a uma cultura agressiva de incentivo ao consumo, também foi considerado importante na avaliação de alguns aspectos de qualidade vida, principalmente para os profissionais que enfrentam dificuldades financeiras para a manutenção da família, afetando aspectos de auto-estima e bem-estar emocional. Cita-se como exemplos o auxiliar de serviços gerais, que disse se sentir frustrado por "não realizar algum sonho" (suj.
5) ou de não satisfazer sua "vontade de tê, alguma coisa..." (suj. 5) e o sujeito 11, pedreiro, que passou a se considerar uma pessoa desonesta pelas dificuldades em cumprir seus compromissos de ordem financeira.

As mesmas limitações são enfrentadas de forma diferente pelos profissionais com maior qualificação profissional e melhor condições materiais de vida, que de certa forma, conseguem superar suas frustrações atribuindo ao trabalho aspectos positivos e nobres, como as representações do trabalho enquanto forma de aprendizagem, que superam as expectativas de remuneração. Identifica-se ainda, que estes profissionais exercem um maior controle sobre o consumo de supérfluos, através do planejamento do orçamento familiar.

Portanto, nestas Unidades Temáticas, além das desigualdades sociais, encontrou-se representada a lógica que sustenta a necessidade de consumo e faz com que o trabalho seja o depositário das expectativas de ascensão social para o trabalhador e sua família, garantindo assim que se mantenha produzindo e adaptado às contradições sociais. Além disso, pode-se perceber o impacto das contradições sociais na formação da subjetividade, que faz com que o trabalhador se sinta impotente e culpado pelo não atendimento de suas necessidades sociais e da família, que por sua vez são criadas para a manutenção do consumo e do modo de produção.

O grupo com menor qualificação também atribuiu ao trabalho a possibilidade de inserção social, através da ampliação dos vínculos sociais, que favorecem a identificação de contextos diferenciados e a expressão da afetividade. Numa outra direção, o trabalho para os profissionais mais qualificados, em função do nível de exigências e pressões a que são submetidos, pareceu representar uma ameaça às relações sociais estabelecidas fora do contexto de trabalho, exigindo uma constante mediação entre atender às necessidades da família e às exigências da atividade profissional.

Sobre estes resultados, foi identificado o movimento inverso que ocorre nas relações estabelecidas entre o trabalho e as outras esferas sociais, principalmente com a esfera familiar, para os grupos diferenciados segundo o nível de qualificação.

As relações sociais para os profissionais com 


\section{Lícia Barcelos de Souza}

menos qualificação pareceram significar a possibilidade de reapropriação da subjetividade, enquanto exercício da afetividade, perdida no enfrentamento das dificuldades associadas ao contexto de vida.

Num movimento inverso, os profissionais com maior qualificação demonstraram se sentir expropriados pelo trabalho, recursos esses de afetividade e de disposição interna, necessários para $\mathrm{o}$ atendimento das necessidades da família. O depoimento do sujeito 14 ilustra o sentimento de expropriação: "Ninguém vive 24 horas trabalhando e sai disso impune”. (analista de comunicação social)

Com relação a esta questão, Antunes (1999) discute o quanto que as novas formas de organização do trabalho, determinadas pela constante inovação tecnológica e complexidade das atividades, vem transferindo para os trabalhadores a dicotomia entre o pensar e o fazer, fazendo com que as empresas se apropriem cada vez mais das capacidades intelectuais e afetivas daqueles trabalhadores que se dedicam às atividades profissionais mais qualificadas: "Neste contexto, o trabalho intelectual que participa do processo de criação de valores encontra-se também sob a regência do fetichismo da mercadoria”. (pág. 129)

No grupo de profissionais com menor qualificação foram identificadas as representações do trabalho enquanto indicador de boa saúde e elemento que facilita o enfrentamento de desequilíbrios psicológicos. Como pode-se constatar, na sociedade capitalista, o trabalho passa a representar para os trabalhadores, com piores condições de vida, uma alternativa importante para obtenção de apoio social e psicológico: "depois dessa tragédia, que eu considero uma tragédia na minha vida, se num fosse o meu trabalho, acho que eu tinha ficado doida" (cozinheira)

Mais do que a obtenção de apoio social retoma-se nas falas destes profissionais a preocupação em se manterem produtivos, sendo a boa saúde a condição básica para a sobrevivência. A fala do sujeito 12 ilustra este ponto de referência:

"O trabalho? O trabalho pra mim é tudo. Eu com saúde, em primeiro lugar saúde, né? Pra você podê trabalhá, né? Porque se você não tem a saúde você num tem o serviço, trabalho. O trabalho é importante na minha vida. Eu gosto." (pedreiro)
Assim, deparam-se, novamente, com as relações estabelecidas entre trabalho e saúde para os profissionais com menor qualificação, discutidas anteriormente em seus aspectos determinantes da qualidade de vida.

As representações sobre o trabalho enquanto possibilidade de recuperação da intencionalidade, através do exercício da capacidade de raciocínio e de participação e autonomia sobre o processo, pareceram ser determinadas pela especialização, que acaba diferenciando o status dos profissionais no seu grupo e na Organização. Este foi o ponto comum identificado nas características dos contextos de trabalho dos sujeitos donos das falas que compuseram esta Unidade Temática. Não se pode deixar de considerar a política de estabilidade de emprego, presente na maioria das Instituições públicas, que cria um ambiente propício para que os profissionais se sintam pouco ameaçados pelas crises no mercado de trabalho externo.

Para os profissionais com maior qualificação o trabalho também pareceu representar um elemento que contribui para a formação da identidade e para $o$ reconhecimento de si mesmo, compreendendo a expressão da subjetividade no fazer, o sentimento de utilidade social, o reconhecimento das próprias habilidades e também a principal referência para a formação de um auto-conceito.

No conjunto das falas, pode-se observar que o trabalho é percebido dentro de um movimento dialético onde ele determina a subjetividade e ao mesmo tempo é determinado por ela (Minayo, 1993). Este mesmo movimento é percebido nas representações da determinação do contexto de vida sobre os significados que o trabalho adquire. Porém, neste movimento, se apresenta a determinação de uma concepção reificada (Lukács, 1974), que naturaliza e perpetua a importância e o valor do homem produtivo.

As relações estabelecidas entre o trabalhador e as várias dimensões da organização do trabalho mostraram-se permeadas pelas contradições entre valores individuais e coletivos, entre espaço público e privado e entre formação da subjetividade e condições materiais de vida e de trabalho.

Sob a perspectiva deste trabalho, o nível de qualificação profissional representou uma dimensão de análise importante sobre as formas como a Orga- 
nização do Trabalho, associada ao contexto social e familiar, tratam as questões relacionadas aos diferentes subgrupos. Além das determinações das diferenças sociais, foi possível identificar as estratégias que os profissionais utilizam para a conciliação entre os "dois mundos", que se resumem em iniciativas individualizadas voltadas para a recuperação do tempo de convivência familiar e lazer. Ainda sobre esta questão, foi possível identificar o quanto o trabalho determina a "vida fora" do trabalho.

Em termos de uma perspectiva que considera a prática profissional em seus aspectos determinados pela organização social, econômica e política, as informações obtidas nas investigações poderão subsidiar a compreensão das formas de enfrentamento e consciência das contradições presentes na organização do trabalho, onde o "papel do trabalho" na vida das pessoas passa a ser enfocado no contexto das determinações sociais, presentes na expressão da subjetividade.

\section{Referências Bibliográficas}

Angerami-Camon, V.A. (1996). Crise, trabalho e saúde mental no Brasil. São Paulo: Traço.

Antunes, R. (1999). Os sentidos do trabalho: ensaio sobre a afirmação e a negação do trabalho. São Paulo: Boitempo Editorial.

Braverman, H. (1987). Trabalho e capital monopolista: a degradação do trabalho no século XX. Rio de Janeiro: Guanabara.

Caldana, A.C.F. (2000). Desemprego e qualidade de vida: estratégias de inclusão social e sobrevivência. Dissertação de Mestrado, Universidade de São Paulo, Ribeirão Preto.

Carmo, P. S. (1992). A ideologia do trabalho. São Paulo: Moderna.

Chan, B.K., Lai, G., Ko, Y.C. \& Kam, W.B. (2000). Work stress among six professional groups: the Singapore experience. Social Science \& Medicine, 50, 1415 - 1432.

Faerstein, E. (2000). O debate qualidade de vida e saúde: outros aspectos a considerar. Ciência \& Saúde Coletiva, 5(1), 22 - 24.
Figueiredo, M.A.C. (1998). Qualificação do trabalho e avaliação do desempenho.[Apostila] $3^{\circ}$ Unidade. Seleção e Treinamento na Indústria I. Curso de Graduação em Psicologia. Departamento de Psicologia e Educação, Faculdade de Filosofia Ciências e Letras de Ribeirão Preto, Universidade de São Paulo.

Fioroni, L.N. (2000). Modos de enfrentamento da aids e condições de vida: estudo baseado em fatores de personalidade e hierarquia de necessidades. Dissertação de Mestrado, Universidade de São Paulo, Ribeirão Preto.

Fleck, M.P.A., Leal, O.F., Louzada, S., Xavier, M., Chachamovich, E., Vieira, G. Santos, L. \& Pinzon, V. (1999). Desenvolvimento da versão em português do instrumento da avaliação de qualidade de vida da OMS (WHOQOL-100). Revista Brasileira de Psiquiatria, 21(1), 19-28. Ou: [on line] www.hcpa.ufrgs.br/psiq/ whoqoll.html, 20/07/1999.

Gorz, A. (Org) (1989). Crítica da divisão do trabalho. São Paulo: Martins Fontes.

Lacaz, F.A.C. (2000). Qualidade de vida no trabalho e saúde/doença. Ciência \& Saúde Coletiva, 5(1), 151-161.

Lukács, G. (1974). História e consciência de classe: estudos de dialética marxista. Porto: Publicações Escorpião.

Minayo, M.C.S. (1993). O desafio do conhecimento: pesquisa qualitativa em saúde. São Paulo Rio de Janeiro: Hucitec - Abrasco.

Ministério do Trabalho e do Emprego (2000). Classificação brasileira de ocupações. [on line] www.mtb.gov.br, 21.07.2000.

Sampaio, J.R. (Org.) (1999). Qualidade de vida, saúde mental e psicologia social: estudos contemporâneos II. São Paulo: Casa do Psicólogo.

Seligman-Silva, E. (1986). Saúde mental e trabalho. Em S.A. Tundis \& N.R. Costa (orgs.), Cidadania e loucura: políticas de saúde mental no Brasil (pp. 217-288). Petrópolis, Rio de Janeiro: Vozes. 
232 Lícia Barcelos de Souza

Seligman-Silva, E. (1994). Desgaste mental no trabalho dominado. Rio de Janeiro - São Paulo, UFRJ: Cortez.

Souza, L.B. (1995). Atitudes frente ao trabalho e indicadores de saúde mental: um estudo.em função de diferenças entre sexos e níveis de escolaridade. Dissertação de Mestrado, Universidade de São Paulo, Ribeirão Preto.

Tamaki, E.M. (2000). Qualidade de vida: individual ou coletiva? Ciência \& Saúde Coletiva, 5(1), 20 -22 .

Universidade de São Paulo. Plano de classificação de funções. On line: www.usp.br, 21.07.2000.

Villalobos, A. (1978). Classes Sociais e Trabalho Produtivo. Rio de Janeiro: Paz e Terra/São Paulo, CEDEC.

O trabalho apresentado é parte dos resultados obtidos na pesquisa realizada entre fevereiro de 1996 e março de 2001, para fins de obtenção do título de Doutor, junto ao Programa de Pós-Graduação em Psicologia, do Departamento de Psicologia e Educação da FFCLRP-USP. 